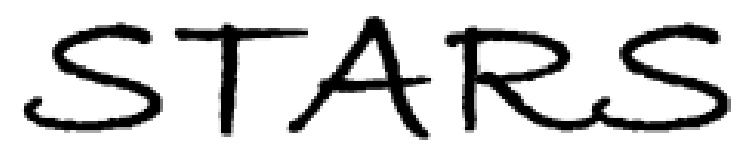

University of Central Florida

STARS

$1-1-1993$

\title{
Wave-Guiding In Substrate Supported And Freestanding Films Of Insoluble Conjugated Polymers
}

Silvia Mittler-Neher

University of Central Florida

Akira Otomo

University of Central Florida

George I. Stegeman

University of Central Florida

Charles Y. -C. Lee

Rajeev Mehta

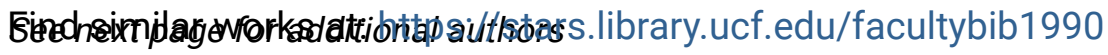

University of Central Florida Libraries http://library.ucf.edu

This Article is brought to you for free and open access by the Faculty Bibliography at STARS. It has been accepted for inclusion in Faculty Bibliography 1990s by an authorized administrator of STARS. For more information, please contactSTARS@ucf.edu.

\section{Recommended Citation}

Mittler-Neher, Silvia; Otomo, Akira; Stegeman, George I.; Lee, Charles Y. -C.; Mehta, Rajeev; Agrawal, Ashwini K.; and Jenekhe, Samson A., "Wave-Guiding In Substrate Supported And Freestanding Films Of Insoluble Conjugated Polymers" (1993). Faculty Bibliography 1990s. 859.

https://stars.library.ucf.edu/facultybib1990/859

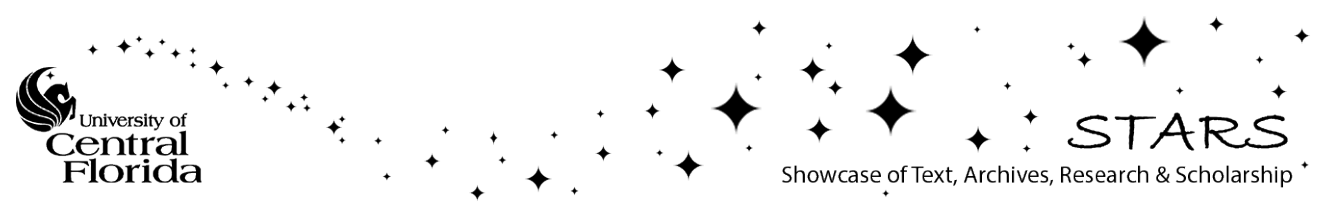




\section{Authors}

Silvia Mittler-Neher, Akira Otomo, George I. Stegeman, Charles Y. -C. Lee, Rajeev Mehta, Ashwini K. Agrawal, and Samson A. Jenekhe 


\section{Waveguiding in substrate supported and freestanding films of insoluble conjugated polymers}

Cite as: Appl. Phys. Lett. 62, 115 (1993); https://doi.org/10.1063/1.109342

Submitted: 21 May 1992 . Accepted: 27 October 1992 . Published Online: 04 June 1998

Silvia Mittler-Neher, Akira Otomo, George I. Stegeman, Charles Y.-C. Lee, Rajeev Mehta, Ashwini K. Agrawal, and Samson A. Jenekhe

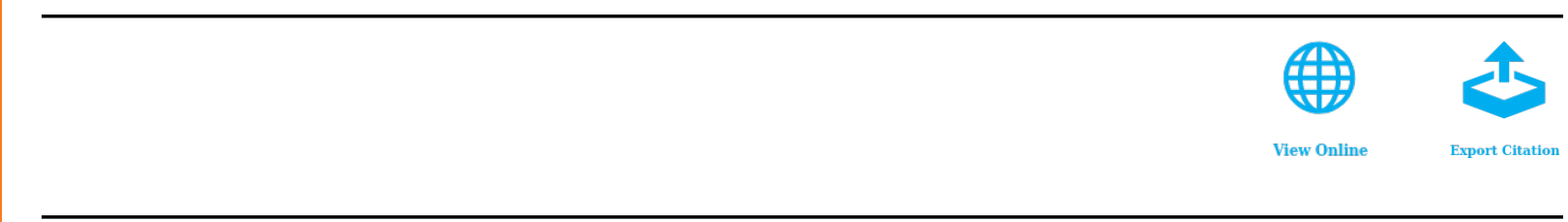

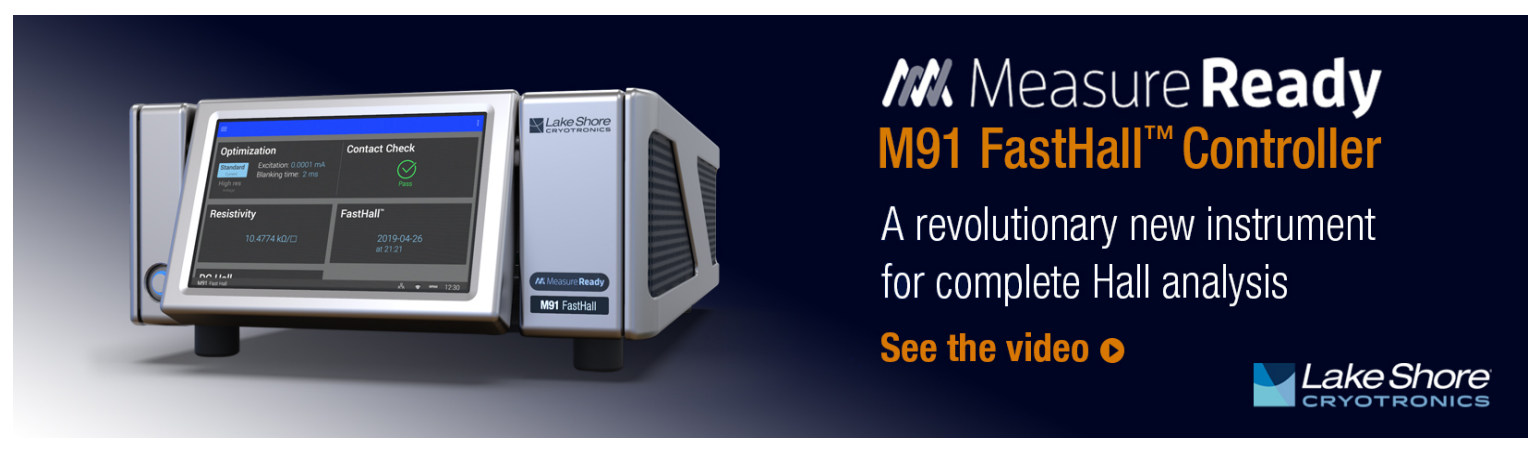




\title{
Waveguiding in substrate supported and freestanding films of insoluble conjugated polymers
}

\author{
Silvia Mittler-Neher, Akira Otomo, and George I. Stegeman \\ Center for Research in Electro-Optics and Lasers, University of Central Florida, 12424 Research \\ Parkway, Orlando, Florida 32826 \\ Charles Y.-C. Lee L) $^{\text {a) }}$ \\ Air Force Material Laboratory, WL/MLBP, Wright-Patterson AFB, Ohio 45433 \\ Rajeev Mehta \\ Adtech Research, Dayton, Ohio 45432
}

Ashwini K. Agrawal and Samson A. Jenekhe

Department of Chemical Engineering, 206 Gavett Hall, University of Rochester, Rochester, New York 14627

(Received 21 May 1992; accepted for publication 27 October 1992)

We demonstrate that waveguiding is possible in substrate supported and freestanding films of insoluble conjugated polymers. Photoresist gratings were used to couple $1.06-1.53 \mu \mathrm{m}$ radiation into the waveguides allowing the refractive indices, the birefringence, and the linear losses to be measured.

Nonlinear optical interactions in waveguides such as all optical switching have attracted interest in the last few years. Various classes of materials have been investigated for that purpose. ${ }^{1}$ Of these, polymeric materials are very attractive because they can be tailored by chemists to improve desired properties such as large $\chi^{(3)}$ values, material processability into waveguides, low linear losses, and a relatively high refractive index $n$ which assures good field confinement in the waveguide. ${ }^{2}$ Processability of polymers for waveguide applications means the manufacturing of thin films of high optical quality with a homogeneous thickness, usually by spincoating out of solution. ${ }^{3}$ However many of the most nonlinear polmers, for example poly ( $\mathrm{p}$ phenylene benzobisthiozole) (PBZT) are not soluble in common solvents. ${ }^{4,5}$ Although it has been shown that waveguides can be made from single-crystal PTS, it is commonly believed by researchers in the field that such insoluble conjugated polymers will not be useful for nonlinear waveguiding due to large scattering and absorption losses, as well as the difficulty in making waveguides out of them. ${ }^{6}$ In this letter we show that waveguides can indeed be made from insoluble polymers, and that the waveguide losses, although still high on these initial films, are promising.

In this work we used two different techniques to fabricate thin films of insoluble polymers: by extrusion ${ }^{7}$ and by complexation mediated processing. ${ }^{79}$ Films made by these methods can either be supported by a substrate resulting in the usual slab waveguide structures, or can be freestanding, yielding a waveguide with no thickness cutoff for the $\mathrm{TE}_{0}$ mode. ${ }^{10}$ Waveguide coupling into these waveguides can be achieved with gratings ion milled into the substrate prior to film deposition, or by fabricating photoresist gratings on top of the film.

Both pure poly(p-phenylene benzobithiozole)

\footnotetext{
"Current address: Chemistry and Atmospheric Science, Air Force Office of Scientific Research, Bolling Air Force Base, Washington DC 203326448.
}

(PBZT) as well as mixed 50:50 with nylon (50:50) was extruded into foils and stretched onto plastic rings (diameter around $20 \mathrm{~mm}$ ). ${ }^{7}$ For the substrate supported waveguides the ring was subsequently flled with a transparent epoxy material $(n=1.564$ at $632.8 \mathrm{~nm})$. For fabricating coupling gratings on top of the waveguides, a 200 $\mathrm{nm}$ thick layer of positive photoresist was spincoated at 3000 RPM and then dried at room temperature for 2-3 days. Exposing the photoresist film to a holographic grating pattern $(\Lambda=1000 \mathrm{~nm})$, chemically developing the photoresist and finally removing all remaining photoresist by exposing the rest of the sample with near-UV radiation provides a waveguide with a photoresist grating on top. ${ }^{11}$

PBZT and poly[2,2'-(1,4-phenylene)-6,6'bis (4phenylquinoline)] (PPPQ) were used to make waveguide samples. They were spincoated from a solution of their complexes onto a fused silica substrate into which a grating had been previously ion milled. ${ }^{8-10}$ After spinning, further chemical treatment of the samples by washing in water or methanol removed the complexed groups from the film to achieve a pure insoluble PBZT or PPPQ waveguide.

PPPQ, starting again as a complex in solution, was also fabricated into a freestanding film cast in a supporting frame. Additional treatment to remove the complexes was also used here. ${ }^{9}$ A photoresist grating was fabricated on top by the same methods described above.

All samples were used as slab waveguides without any further confinement in the lateral dimension. The experimental setup for waveguide coupling is described elsewhere. ${ }^{11}$ In this study both incident light polarizations, $s$ and $p$, were used to couple into TE and TM modes, respectively, at $1.064,1.319$, and $1.535 \mu \mathrm{m}$ (Amoco lasers). The losses were measured by imaging the streak with an IR sensitive camera onto a video monitor. With the help of a computer controlled frame grabber system, the intensity profile along the streak was measured and fitted to an exponential decay providing the losses in $\mathrm{dB} / \mathrm{cm}$.

It was very easy to grating couple both $s$ - and 


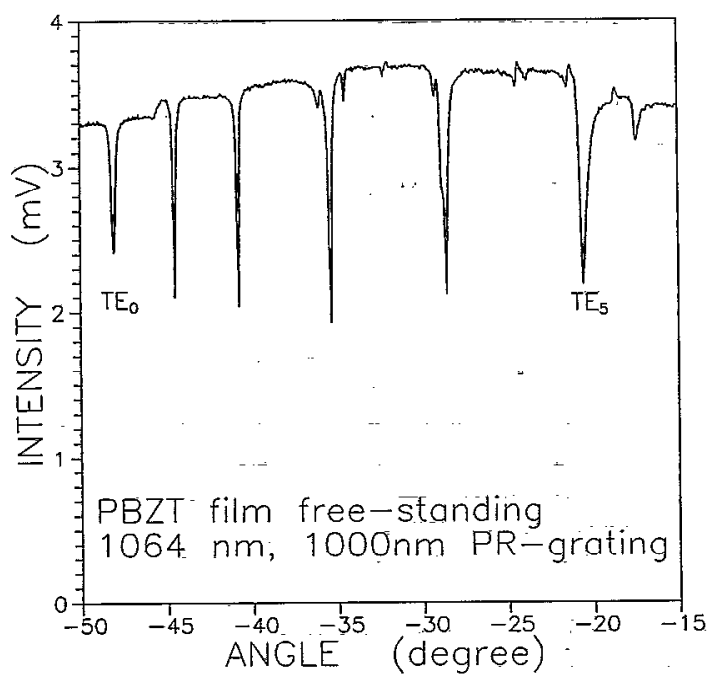

FIG. 1. Mode profile (transmission through the waveguide vs incidence angle) for a freestanding PBZT film at $\lambda=1.064 \mu \mathrm{m}$.

$p$-polarized radiation into all of the waveguide samples using photoresist gratings. The coupling efficiency was not measured directly, but was comparable to the typical $1 \%-$ $10 \%$ efficiencies obtained for coupling via ion-milled gratings. This was deduced by comparing the coupling dips for both types of gratings. Shown in Fig. 1 is a typical mode profile (transmission through the film versus incidence angle) at $\lambda=1.064 \mu \mathrm{m}$ for an extruded freestanding waveguide of PBZT with a photoresist grating as a coupler. It exhibits the sharp and deep coupling dips associated with substrate gratings. ${ }^{12}$ To the best of our knowledge, this is the first demonstration of mode excitation in freestanding waveguide films.

Several guided modes were observed at the three wavelengths used and propagation streaks of a few $\mathrm{mm}$ up to about a $\mathrm{cm}$ in length could clearly be seen with the IR viewer in all waveguides, except the spincoated PBZT film. However, grating coupling dips were also observed for this sample, but the losses were so high that no streak could be identified, and therefore no losses were measured. The refractive indices and losses for the substrate supported samples are summarized in Table I and for the freestanding guides in Table II. The refractive indices deduced for the extruded PBZT sample with the epoxy substrate contains some uncertainty because the index dispersion is not known for the substrate material. For al calculations, the value at $632.8 \mathrm{~nm}$ was used.

Figure 2 shows the longest streak found in any of the samples: PBZT extruded, freestanding studied at $1.3 \mu \mathrm{m}$

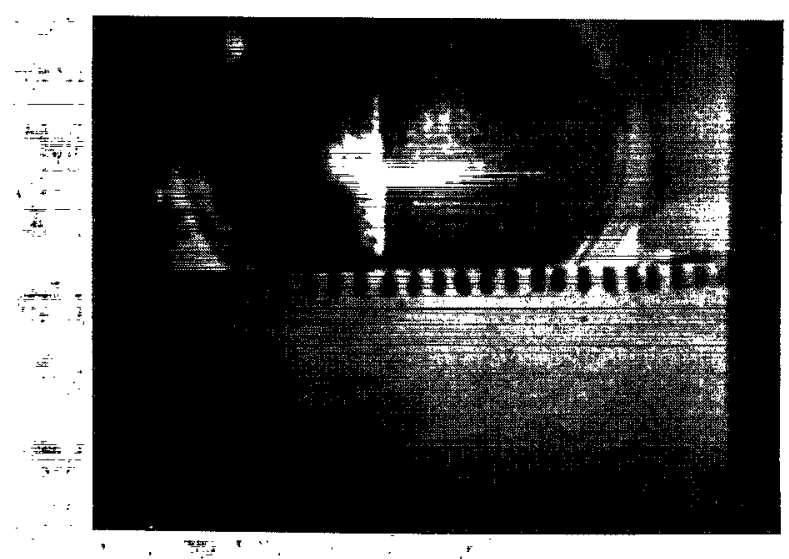

FIG. 2. Photograph of the streak with the lowest measured loss of 12.8 $\mathrm{d} \overline{\mathrm{B}} / \mathrm{cm}$ at a wavelength of $1.3 \mu \mathrm{m}$ in a PBZT, freestanding extruded film. A scale with $1 \mathrm{~mm}$ divisions is shown below.

with a measured loss of $12.8 \mathrm{~dB} / \mathrm{cm}$. In general, the losses increased with increasing mode number for TE as well as TM modes. In most cases the TM modes were less lossy than the TE modes of the same mode number. The spin coated PPPQ film was the lossiest waveguide studied.

We have found that extruded PBZT foils, both substrate supported and freestanding can be used as waveguides. Casting and spincoating conjugated polymer films out of complexation mediated solutions also led to waveguiding films. Grating coupling through a photoresist grating on top of the waveguide material showed good performance and should be a useful approach for cases where prism coupling, bleaching a grating structure into the material, or the end fire coupling does not work.

In all the samples, the refractive indices decreased with increasing wavelength, that is, as the wavelength separation from the absorption bands in the visible and ultraviolet increased. The birefringence, the difference between the TE and TM polarized refractive indices, was dependent on the sample preparation. Small differences in the birefringence were found in samples made by the three different methods. The largest birefringences were found for the extruded film of pure PBZT $(\Delta n=0.169)$ and the spincoated PPPQ film $(\Delta n=0.18)$. A lower value was found for the extruded PBZT/nylon mixture $(\Delta n=0.141)$ and the cast PPPQ sample $(\Delta n=0.138)$. The spincoated PBZT film exhibits the lowest birefingence of $\Delta n=0.063$.

The reason for this behavior lies in the fabrication process itself. The extrusion process leads to strong directional orientation of the molecules which tend to follow the applied stress and get partial alignment along the extrusion

TABLE I. Substrate supported films.

\begin{tabular}{|c|c|c|c|c|c|c|}
\hline Material & Method & $\begin{array}{c}\text { Thickness } \\
{[\mu \mathrm{m}]}\end{array}$ & $\begin{array}{l}\text { Wavelength } \\
{[\mu \mathrm{m}]}\end{array}$ & $\stackrel{n}{n}$ & $\begin{array}{c}n \\
(\mathrm{TM})\end{array}$ & $\begin{array}{l}\text { Losses }[\mathrm{dB} / \mathrm{cm}] \\
\min -\max \end{array}$ \\
\hline \multirow[t]{2}{*}{ PBZT } & extruded & 2.87 & 1.064 & $1.8 \overline{15}$ & 1.629 & $29.8-58.9$ \\
\hline & & & 1.319 & & 1.627 & $15.7-31.0$ \\
\hline PBZT & spincoated & 2.0 & 1.064 & 1.742 & 1.679 & no streak \\
\hline PPPQ & spincoated & 1.0 & 1.064 & 1.743 & 1.563 & $21.4-42.2$ \\
\hline
\end{tabular}


TABLE II. Freestanding films.

\begin{tabular}{|c|c|c|c|c|c|c|}
\hline Material & Method & $\begin{array}{c}\text { Thickness } \\
{[\mu \mathrm{m}]}\end{array}$ & $\begin{array}{l}\text { Wavelength } \\
{[\mu \mathrm{m}]}\end{array}$ & $\begin{array}{c}n \\
\text { (TE) }\end{array}$ & $\begin{array}{c}n \\
(\mathrm{TM})\end{array}$ & $\begin{array}{c}\text { Losses }[\mathrm{dB} / \mathrm{cm}] \\
\min -\max \end{array}$ \\
\hline \multirow[t]{3}{*}{ PBZT } & \multirow[t]{3}{*}{ extruded } & \multirow[t]{3}{*}{2.50} & 1.064 & 1.811 & 1.642 & $24.1-56.8$ \\
\hline & & & 1.319 & 1.791 & 1.628 & $12.8-43.9$ \\
\hline & & & 1.535 & 1.788 & 1.623 & $15.7-58.1$ \\
\hline \multirow[t]{3}{*}{ PPPQ } & \multirow[t]{3}{*}{ cast } & \multirow[t]{3}{*}{5.4} & 1.064 & 1.775 & 1.637 & $22.4-57.8$ \\
\hline & & & 1.319 & 1.727 & 1.594 & $27.3-53.9$ \\
\hline & & & 1.535 & 1.702 & 1.588 & $28.6-66.5$ \\
\hline \multirow[t]{3}{*}{ PBZT/nylon } & \multirow[t]{3}{*}{ extruded } & \multirow[t]{3}{*}{1.6} & 1.064 & 1.760 & 1.619 & $15.5-87.3$ \\
\hline & & & 1.319 & 1.748 & 1.619 & $15.7-51.6$ \\
\hline & & & 1.535 & 1.650 & 1.613 & $18.8-35.8$ \\
\hline
\end{tabular}

direction. In the spincoating process the molecules are oriented by the substrate surface, the spinning stress, and in our case also by the volume shrinkage which occurs during removal of the complexes. These factors contribute different amounts for different materials as evidence by the difference between the PPPQ and PBZT samples and prior work on polyimides. ${ }^{13}$ The cast films are influenced only by the surface without any stress or volume shrinkage.

This difference in birefringence induced in the same material by different preparation methods [e.g., PPPQ at $1.064 \mu \mathrm{m}: 0.18$ (spun) to 0.138 (cast)] may offer some flexibility for device construction depending on whether a homogeneous or inhomogeneous refractive index is needed.

As indicated in the tables, we found a large variation in the waveguide losses in any given sample. In many cases, inclusions, bubbles, domains, etc. were visible to the eye and coupling into such regions produced very large losses. Furthermore, we found that the losses had a very strong dependence on the mode number and wavelength. For thick films which support many modes, the higher modes exhibited the largest losses found in the tables. The inverse holds for longer wavelengths: with increasing wavelength fewer modes propagate and the maximum loss drops. In general the lowcst measured losses decrease from 1.06 to $1.3 \mu \mathrm{m}$, but rise again for $1.5 \mu \mathrm{m}$, probably because overtones of vibrational modes start to become important at this wavelength, leading to additional linear absorption.

The measured losses of these new waveguides made from insoluble conjugated polymers are still too high for device applications. However, at this stage it is surprising that modes can be excited at all in guides made from these materials and by these techniques. Further refinement of the fabrication techniques should lead to substantially lower losses. The mixture of PBZT with nylon gives the foils a slightly rubbery texture and seems to yield a better stretched film, resulting in overall lower losses for the lower modes. This is in good agreement with the observations of Mehta et al. who found that films of PBZT/nylon mixtures had a better optical film quality than pure PBZT films. $^{7}$

We have demonstrated waveguiding in the $1.0-1.5 \mu \mathrm{m}$ wavelength range in insoluble conjugated polymer films. Substrate supported and freestanding films made by various preparation methods yielded different film structures. Photoresist coupling gratings were successfully used to couple light into these waveguides and characterize their optical properties. Large birefringence was found. Waveguide losses are larger than $10 \mathrm{~dB} / \mathrm{cm}$, and depend on the fabrication technique and wavelength. Minimum losses were observed at $1.3 \mu \mathrm{m}$.

The authors acknowledge the National Science Foundation and the Air Force Office for Scientific Research for financial support, and thank J. Ross for fabricating the gratings.

${ }^{1}$ G. I. Stegeman, E. M. Wright, N. Finlayson, R. Zanoni, and C. T. Seaton, J. Lightwave Technol. 6, 953 (1988).

${ }^{2}$ P. N. Prasad and D. J. Williams, Introduction to Nonlinear Optical Effects in Molecules and Polymers (Wiley, New York, 1991).

${ }^{3}$ K. Rochford, R. Zanoni, Q. Gong, and G. I. Stegeman, Appl. Phys. Left. 55, 1161 (1989).

${ }^{4}$ D. N. Rao, J. Swiatkiewicz, P. Chopra, S. K. Ghoshal, and P. N. Prasad, Appl. Phys. Lett. 48, 1187 (1986).

${ }^{5}$ H. Vanherzeele, J. S. Meth, S. A. Jenekhe, and M. F. Roberts, J. Opt. Soc. Am. B 9, 524 (1992).

${ }^{6}$ M. Thakur and D. M. Krol, Appl. Phys. Lett. 56, 1213 (1990).

${ }^{7}$ R. Mehta and C. Y.-C. Lee, Polymer and Engineering Science (in press).

${ }^{8}$ S. A. Jenekhe, P. O. Johnson, and A. K. Agrawal, Macromolecules 22, 3216 (1989).

${ }^{9}$ A. K. Agrawal and S. A. Jenekhc, Chem. Mater. 4, 95 (1992).

${ }^{10} \mathrm{~T}$. Tamir, Topics in Applied Physics: Integrated Optics (Springer, Berlin, 1979), Vol. 7.

"X. Mai, R. S. Moshrefzahdeh, U. J. Gibson, G. I. Stegeman, and C. T. Seaton, Appl. Opt. 24, 3155 (1985).

${ }^{12}$ M. B. Marques, G. Assanto, G. I. Stegeman, G. R. Möhlmann, E. W. P. Erdhuisen, and W. H. G. Horsthuis, Appl. Phys. Lett. 58, 2613 (1991).

${ }^{13}$ W. M. Prest, Jr. and D. J. Luca, J. Appl. Phys. 50, 6067 (1979); ibid. 51, 5170 (1980). 